\title{
Effect of Honey on Selected Physical and Sensory Properties of Cookies from Cassava-Wheat Composite Flour
}

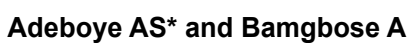

Department of Food Technology, Moshood Abiola Polytechnic, PMB. 2210, Abeokuta, Nigeria

\begin{abstract}
This work assessed the effect of the inclusion of honey as partial sweetener in cookies baked with batter developed from cassava wheat composite flour. A recipe was adapted from previous study and the sugar in the established formulation was there after substituted in the proportions of Honey $(\mathrm{H})$ : Sugar $(\mathrm{S}) 10 \mathrm{H}: 90 \mathrm{~S}, 20 \mathrm{H}: 80 \mathrm{~S}, 30 \mathrm{H}: 70 \mathrm{~S}, 40 \mathrm{H}: 60 \mathrm{~S}$ and $50 \mathrm{H}: 50 \mathrm{~S}$ to obtain different set of recipe respectively. Baked products were subjected to some physical measurements and sensory evaluation. Result obtained indicated significant difference $(P<0.05)$ in flavour and overall acceptability while no significant difference was observed in the other sensory parameters assessed. There were significant difference $(P<0.05)$ in all the physical properties assessed. The study concludes that partial substitution with honey at $20 \%$ level is optimal for an acceptable cookie from cassavawheat composite flour in terms of sensory preference; and that honey substitution improves spread ratio of cookies but increased moisture content of cassava-wheat composite cookies.
\end{abstract}

Keywords: Cassava-wheat flour; Honey; Cookies

\section{Introduction}

Cookies are among the most significant baked products consumed by Nigerians. They are particularly relished as snack food product by children and adults. The increasing importance of snack foods such as cookies in today's eating habit has not been fully exploited [1]. Cookies in particular hold an important position in snack foods due to variety in taste, crispiness and digestibility [2].

Honey is an alternative therapy firmly rooted in ancient medical armamentarium and its anti-microbial properties is evolving 'everyday' [3]. Beyond many health claims and ability to mask any taste deficiency that may have resulted from ingredient interactions, inclusion of honey into bread formulation is reported to offer functional benefits, improve water-binding capacity of dough, provide increased production volumes and improve shelf life of baked products [4-8]. Cookies are prepared from dough developed basically from soft wheat flour and other ingredients like sugar, fat, egg, baking powder and water.

To cut the nation's expense on wheat importation and find wider utilization for the increasingly produced cassava roots, the Federal Government of Nigeria mandated the use of composite cassava-wheat flour for baking by adding minimum of $10 \%$ cassava flour to wheat as a policy.

Several studies have confirmed the possibility of producing baked products from $10 \%$ cassava-wheat composite flour with tremendous success recorded in their physical, sensory and proximate composition [9].

The substitution of a type of sugar by another has typically been studied in food products with the objective of finding a level of replacement that will improve the product characteristics [10]. It was reported [11] that, in some mixtures of honey and pure sugar, substituting $25-50 \%$ of the pure sugar with honey caused a significant change in peak viscosity of unmodified maize starch. In an earlier study, an earlier report [12] pointed out that individual starch gelation characteristic differs in their response to partial or complete substitution of various sugars.

Ingredients modification reflects not only on the chemical composition of foods but also manifests on physical and sensory properties of the food. The latter two properties are essential in sales and marketing of the food products. This current study aims at evaluating the effects of partial substitution of sugar with honey on physical and sensory properties of cookies baked from cassava-wheat composite flour.

\section{Materials and Methods}

Matured (12 months old) sweet (Manihot dulcis) variety of cassava tubers used for the production of cassava flour were obtained from the farm of Moshood Abiola Polytechnic, Abeokuta. Soft wheat (white) flour ("Honeywell" flour mills, Lagos, Nigeria) was purchased from Kuto market in Abeokuta. Other ingredients used include granulated sugar (Dangote groups (Nig) Ltd. Lagos), baking powder, vanilla flavor, eggs and baking fat (Pt Intibucá Sejhtera, Jakarta, Indonesia). Pure natural honey used was obtained from Institute of Vocational Beescraft, Abeokuta.

Cassava flour was prepared by method described for high quality cassava (HQCF) by IITA [13]. Matured cassava roots without rot were selected. They were peeled, washed and grated in a mechanical grater. The pulp obtained was dewatered in a 'muslin' cloth placed in between a screw press. The pulverized material obtained was then spread on trays on thin layer and dried in cabinet dryer (Lukas Engineering Nig. Ltd) at $70^{\circ} \mathrm{C}$ to a constant weight to give a flour of $4 \%$ moisture. The dried pulverized material was then milled to fine powder in a hammer mill. The cassava flour obtained was stored in an airtight container.

$0 \mathrm{H}: 100 \mathrm{~S}=$ cassava wheat composite cookie with $0 \%$ honey (control)

10H: $90 \mathrm{~S}=$ cassava wheat composite cookie with $10 \%$ honey

*Corresonding author: Adedola S Adeboye, Department of Food Technology Moshood Abiola Polytechnic, PMB 2210, Abeokuta, Nigeria, E-mail: dola.adeboye@gmail.com

Received May 20, 2014; Accepted February 16, 2014; Published February 23 , 2014

Citation: Adeboye AS, Bamgbose A (2015) Effect of Honey on Selected Physical and Sensory Properties of Cookies from Cassava-Wheat Composite Flour. J Food Process Technol 6: 459. doi:10.4172/2157-7110.1000459

Copyright: (c) 2015 Adeboye AS, et al. This is an open-access article distributed under the terms of the Creative Commons Attribution License, which permits unrestricted use, distribution, and reproduction in any medium, provided the original author and source are credited. 
20H: $80 \mathrm{~S}=$ cassava wheat composite cookie with $20 \%$ honey

$30 \mathrm{H}: 70 \mathrm{~S}=$ cassava wheat composite cookie with $30 \%$ honey

40H: $60 \mathrm{~S}=$ cassava wheat composite cookie with $40 \%$ honey

50H: $50 \mathrm{~S}=$ cassava wheat composite cookie with $50 \%$ honey

$\mathrm{g}=$ grams

\section{Baking procedure}

Cookies were prepared using the method of Nishiber and Kawakishi [3] with slight modifications. Instead of butter and sugar used in the original formula, margarine was used as fat and part of the sugar was substituted with liquid honey at $10-50 \%$ level. The amount of the ingredients used is indicated in (Table 1). The flour, sugar and baking powder were manually mixed inside a bowl $\left(1000 \mathrm{~cm}^{3}\right)$. Margarine and beaten egg were well creamed manually for about $60 \mathrm{sec}$ and then other dried ingredients were added at once; the weighed honey was then injected into the system and mixed for further $60 \mathrm{sec}$. The batter was shaped using tomato tin $(0.25 \times 35 \mathrm{~mm})$ and baked in table top oven which has been pre-heated to $180^{\circ} \mathrm{C}$ for $20 \mathrm{~min}$. The baked ccokies were allowed to cool on a rack after which they were packaged in a low density polythene bags.

\section{Determination of physical properties}

Cookies diameter (D) and thickness (T) were determined using a venier caliper while cookies weight was determined using an electronic weighing balance. Spread ratio was calculated as D/T $\times 10$ as described by Akubor [6]. For the moisture content; the samples were grounded with mortal and pestle and $2 \mathrm{~g}$ of each sample was placed on the empty stainless steel plate of the moisture analyzer. The moisture content was noted as shown in the digital read out.

\section{Sensory Evaluation}

\section{Multiple comparison test}

Method described by Iwe [14] was adopted for the multiple comparison tests. Cooled fresh cookie samples from the experiment were served to 20 man panel of trained judges. The control sample was marked ' $R$ ' and the test samples were presented in identical containers coded with 3-digit random numbers served simultaneously.

The panelist were asked to compare each test sample with the reference sample and tick the expression that best describe their judgment using the questionnaire provided with respect to flavor, taste, texture, internal and external surface colour of the cookies. After the evaluation, numerical scores were assigned to the expressions of the panelist with 1 as extremely better than, 5 as equal to ' $R$ ' and 9 as extremely poorer than ' $R$ '. The data obtained were then analysed for variance and degree of difference.

\section{Acceptability (Preference) test}

The control sample was coded with a different set of 3-digit random numbers alongside other samples. All the samples were simultaneously presented in identical containers to the panelists in a random order. Panelists were asked to evaluate the entire samples and mark the degree of their acceptability of each sample using the questionnaire provided with a scale of 1 (most acceptable) to 6 as (most unacceptable). The data obtained were then analysed for variance.

\section{Data analyses}

All physical measurements and sensory data were subjected to analysis of variance (ANOVA), using the SPSS 11.0 (Michigan State University, USA) version.

\section{Results and Discussion}

\section{Physical properties}

The physical properties of cookies from the study are presented in Table 2. The mean diameter of the cookies ranged from (38.76-39.44 $\mathrm{mm})$. Although one of the honey-substituted samples (20H: $80 \mathrm{~S})$ had the highest diameter, there was no significant difference $(\mathrm{P}<0.05)$ in the diameter of all the cookie samples. On the other hand, thickness, weight, moisture content and spread ratio of the cookies varied significantly $(\mathrm{P}>0.05)$ from $(4.406-9.211 \mathrm{~mm}),(7.69-9.78 \mathrm{~g}),(2.51-$ $9.23 \%)$ and (43.59-104.47), respectively. It is observable from the result that increasing concentration of honey lowers thickness of cookies but apparently increased the weights. Moisture content and spread ratio increased with progressive honey concentration; this can be attributed to the high moisture content of honey (as compared to granulated sugar) with the dough becoming softer and the ability of the dough to spread thus becoming higher. Same batter weights were used for all samples and hence significant difference in weight of cookies were not 'scientifically' expected. The difference in weight and thickness could have resulted from suspected difference in the matrix created by the honey-sugar mix allowing varying degree of evaporation, gas retention and moisture diffusion abilities of the batter (with progressive increase in honey concentration during baking). The weight difference can further be corroborated by the data on moisture content of cookies as those with higher moisture have higher weight. This phenomena however did not follow an exact linear relationship with honey concentration in the formulation. This is because the moisture content of the honey used (14\%) was factored out in balancing the ingredient formulation for all samples; so the variation could only have arose from the phenomena suggested above. Spread ratio is expressed mathematically as the ratio of the diameter to that of thickness. Literarily, it suggests an indication of how a dough/batter optimally occupies the space available to it during baking. In the context of this study, it gives an idea of the influence of ingredient modification and interaction on the elasticity of the batter. It is not surprising that there was no significant difference in the diameter since the batter were all shaped using same tomato tin $(0.25 \times 35 \mathrm{~mm})$ i.e consistent diameter ; however, since their thicknesses varied significantly, it would reflect on the spread ratio as well. It must be noted that the modified batters in this study are unusual batter system; the elasticity/extensibility of a mixture of glutein and non glutein flour may not behave according to direct scientific expectation. The "hygroscopicity" of sugar/honey, different viscosities of honey sugar mix and moisture diffusivities are also potent enough to affect the spread ratio. The data obtained in

\begin{tabular}{|l|l|l|l|l|l|l|}
\hline & \multicolumn{7}{|c|}{ Composition } \\
\hline Materials & $\mathrm{OH}: 100 \mathrm{~S}$ & $10 \mathrm{H}: 90 \mathrm{~S}$ & $20 \mathrm{H}: 80 \mathrm{~S}$ & $30 \mathrm{H}: 70 \mathrm{~S}$ & $40 \mathrm{H}: 60 \mathrm{~S}$ & $50 \mathrm{H}: 50 \mathrm{~S}$ \\
\hline Wheat flour (g) & 180 & 180 & 180 & 180 & 180 & 180 \\
\hline Cassava flour (g) & 20 & 20 & 20 & 20 & 20 & 20 \\
\hline Margarine (g) & 44 & 44 & 44 & 44 & 44 & 44 \\
\hline Honey (g) & -- & 4 & 8 & 12 & 16 & 20 \\
\hline $\begin{array}{l}\text { Granulated Sugar } \\
\text { (g) }\end{array}$ & 40 & 36 & 32 & 28 & 24 & 20 \\
\hline Salt (g) & 1.4 & 1.4 & 1.4 & 1.4 & 1.4 & 1.4 \\
\hline Baking powder (g) & 2 & 2 & 2 & 2 & 2 & 2 \\
\hline Water (g) & 36 & 36 & 36 & 36 & 36 & 36 \\
\hline Eggs (pcs) & 4 & 4 & 4 & 4 & 4 & 4 \\
\hline
\end{tabular}

Table 1: Formulation of honey-sugar cassava-wheat composite cookies. 
Citation: Adeboye AS, Bamgbose A (2015) Effect of Honey on Selected Physical and Sensory Properties of Cookies from Cassava-Wheat Composite Flour. J Food Process Technol 6: 459. doi:10.4172/2157-7110.1000459

Page 3 of 3

\begin{tabular}{|c|c|c|c|c|c|}
\hline \multirow{2}{*}{ Samples } & \multirow{2}{*}{\begin{tabular}{|l} 
Diameter \\
$(\mathbf{m m})$
\end{tabular}} & \multirow{2}{*}{$\begin{array}{l}\text { Thickness } \\
\text { (mm) }\end{array}$} & \multirow{2}{*}{$\begin{array}{l}\text { Weight } \\
\text { (g) }\end{array}$} & \multirow{2}{*}{$\begin{array}{l}\text { Moisture } \\
\text { content \% }\end{array}$} & \multirow{2}{*}{ Spread ratio } \\
\hline & & & & & \\
\hline 0H: $100 \mathrm{~S}$ & $39.06 \pm 0.01$ & $9.21 \pm 0.12$ & $7.69 \pm 0.01$ & $2.51 \pm 0.05$ & $43.59 \pm 0.01$ \\
\hline $10 \mathrm{H}: 90 \mathrm{~S}$ & $39.11 \pm 0.01$ & $8.45 \pm 0.01$ & $9.11 \pm 0.02$ & $7.44 \pm 0.01$ & $46.86 \pm 0.01$ \\
\hline $20 \mathrm{H}: 80 \mathrm{~S}$ & $39.44 \pm 0.02$ & $8.04 \pm 0.01$ & $9.20 \pm 0.01$ & $4.78 \pm 0.12$ & $53.27 \pm 0.12$ \\
\hline $30 \mathrm{H}: 70 \mathrm{~S}$ & $38.76 \pm 0.01$ & $5.15 \pm 0.01$ & $9.55 \pm 0.01$ & $9.08 \pm 0.01$ & $79.70 \pm 0.03$ \\
\hline $40 \mathrm{H}: 60 \mathrm{~S}$ & $39.06 \pm 0.03$ & $4.41 \pm 0.10$ & $8.30 \pm 0.02$ & $9.08 \pm 0.11$ & $94.14 \pm 0.02$ \\
\hline $50 \mathrm{H}: 50 \mathrm{~S}$ & $39.11 \pm 0.01$ & $4.49 \pm 0.01$ & $9.78 \pm 0.11$ & $9.23 \pm 0.12$ & $104.47 \pm 0.11$ \\
\hline LSD & 0.94 & 0.78 & 0.72 & 0.43 & 7.18 \\
\hline
\end{tabular}

Means in the same column not followed by same superscript letter are significantly different $(P<0.05) \mathrm{mm}=$ millimeters, $g=$ grams, \%=percentage.

Table 2: Physical properties of cookies baked from cassava-wheat composite flour with different honey levels.

\begin{tabular}{|c|c|c|c|c|c|}
\hline Samples & Flavour & Taste & Texture & $\begin{array}{c}\text { Internal } \\
\text { surface } \\
\text { colour }\end{array}$ & $\begin{array}{c}\text { External } \\
\text { surface } \\
\text { colour }\end{array}$ \\
\hline $10 \mathrm{H}: 90 \mathrm{~S}$ & $1.90 \pm 0.01$ & $2.30 \pm 0.01$ & $4.20 \pm 0.10$ & $2.70 \pm 0.01$ & $3.20 \pm 0.03$ \\
\hline $20 \mathrm{H}: 80 \mathrm{~S}$ & $2.90 \pm 0.13$ & $3.30 \pm 0.01$ & $4.20 \pm 0.20$ & $3.00 \pm 0.06$ & $4.10 \pm 0.01$ \\
\hline $30 \mathrm{H}: 70 \mathrm{~S}$ & $3.20 \pm 0.42$ & $3.60 \pm 0.05$ & $3.90 \pm 0.01$ & $3.80 \pm 0.01$ & $4.00 \pm 0.01$ \\
\hline $40 \mathrm{H}: 60 \mathrm{~S}$ & $3.40 \pm 0.94$ & $3.50 \pm 0.10$ & $4.80 \pm 0.03$ & $2.70 \pm 0.04$ & $3.80 \pm 0.04$ \\
\hline $50 \mathrm{H}: 50 \mathrm{~S}$ & $4.20 \pm 0.01$ & $4.00 \pm 0.11$ & $4.90 \pm 0.01$ & $3.70 \pm 0.01$ & $3.50 \pm 0.02$ \\
\hline LSD & 0.98 & 1.82 & 1.27 & 1.2 & 1.12 \\
\hline
\end{tabular}

Means in the same column not followed by same superscript letter are significantly different $(P<0.05)$.

Table 3: Mean sensory score of honey-cassava wheat composite cookies

\begin{tabular}{|c|c|c|c|c|c|c|}
\hline Samples & $0 \mathrm{H}: 100 \mathrm{~S}$ & $10 \mathrm{H}: 90 \mathrm{~S}$ & $20 \mathrm{H}: 80 \mathrm{~S}$ & $30 \mathrm{H}: 70 \mathrm{~S}$ & $40 \mathrm{H}: 60 \mathrm{~S}$ & $50 \mathrm{H}: 50 \mathrm{~S}$ \\
\hline Score & $1.50 \pm 0.01$ & $3.10 \pm 0.03$ & $2.70 \pm 0.02$ & $3.60 \pm 0.02$ & $4.70 \pm 0.01$ & $5.40 \pm 0.01$ \\
\hline LSD & \multicolumn{5}{|c|}{0.96} \\
\hline
\end{tabular}

Means not followed by same superscript letter are significantly different $(P<0.05)$

Table 4: Mean Sensory Scores of honey-cassava-wheat cookies (Overall Acceptability).

this study on the diameter, thickness and spread ratio are pointers to the fact that honey inclusion (honey-sucrose mixture) has significant influence on the thickness and spread ratio of cookies produced. This is consistent with the findings reported in previous study.

\section{Sensory attributes}

The mean scores of multiple comparisons of honey-cassava-wheat composite cookies are presented in Table 3. It is evident that, inclusion of honey in the formulation has no significant effect $(\mathrm{P}>0.05)$ on all the sensory parameters except for flavour. This suggests that inclusion of honey did not significantly affect the taste, texture, internal and external surface colour of the cookies. Means sensory scores of overall acceptability of the cookies are presented in (Table 4). Cookies baked with $20 \%$ honey substitution level had the closest acceptability to the control sample (i.e cookies baked with $100 \%$ sugar). It is however obvious from (Tables 3 and 4) that it is not only 'taste' that suggest overall acceptability of cookies as the sample with the highest score in the multiple comparison test scored least in the overall acceptability test. This also points to the fact that the higher the inclusion of honey in the batter, the less acceptable the cookies becomes.

\section{Conclusion}

Although inclusion of liquid honey in cookies formulation tends to lower overall acceptability of the products; this study has indicated that cookies prepared from composite flour and liquid honey is capable of improving potential for sales; as it has positive effect on the weight and spread ratio which are among the first physical appeal that would spur consumers to buy. However, honey at partial substitution level of $10-50 \%$ does not have significant effect on most sensory properties of cookies.

\section{References}

1. Chinma CE, Gernah DI (2007) Physicochmical and sensory properties of cookies produced from cassava/soybean/mango composite flours. Journal of Food Technology 5: 256-260.

2. Hussain S, Muhammad AF, Sadiq Butt M, Khan M, Asghar A (2008) Physical and sensoric attributes of flaxseed flour supplemented cookies. Turk J Biol 30 87-92.

3. Shittu TA, Raji AO, Sanni LO (2007) Bread from composite cassava-wheat flour: Effect of baking time and temperature on some physical properties of bread loaf. Food Research International 40: 280-290.

4. Addo K (1997) Effects of honey type and level on the baking properties of frozen wheat flour doughs. Cereals Food World 42: 36-40.

5. Adeboye AS, Babajide JM, Shittu TA, Omemu AM, Oluwatola OJ (2012) Effect Of honey as partial sugar substitute on pasting properties, consumer preference and shelf stability of cassava-wheat composite bread. Nigerian Food Journal 31: 1.

6. Akubor PI (2004) Chemical and functional properties of soybean/maize flour blends for food preparations. Proceedings of the $28^{\text {th }}$ Annual Conference of Nig. Inst. Of Food Sci Tech 46-47.

7. Defloor I, Leijskens R, Bokanga M, Delcour JA (1995) Impact of genotype, crop age and planting season on the breadmaking and gelatinization properties of flour produced from cassava (Manihot esculenta Crantz) flour. Journal of the Science of Food and Agriculture 68: 167-174.

8. Foster RJ (2008) Fortification on the rise. Bulletin of Food Product Design official media site of supply side innovative ingredient international.

9. Nishiber S, Kawakishi S (1990) Effects of dough materials on flavor formation in baked cookies. J. Food Sci 55: 409-412.

10. Torley PJ, Rutgersb RPG, Arcya BD, Bhandar BR (2004) Effect of honey types and concentration on starch gelatinization. Lebensm.-Wiss. u.-Technol 37: 161-170.

11. Torley PJ, Van der Molen F (2005) Gelatinization of starch in mixed sugar systems. LWT 38: 762-771.

12. Shultz SM (2009) Honey as a remedy in alternative and complimentary therapies. Journal Of Consumer Health 13: 287-294.

13. IITA (2005) International Institute for tropical agriculture. Production of high quality unfermented cassava flour in Nigeria.

14. Iwe OM (2002) Handbook of sensory methods and analysis. Joint communications services, Enugu, Nigeria. 